\title{
A luta territorial dos indígenas da Terra Maró
}

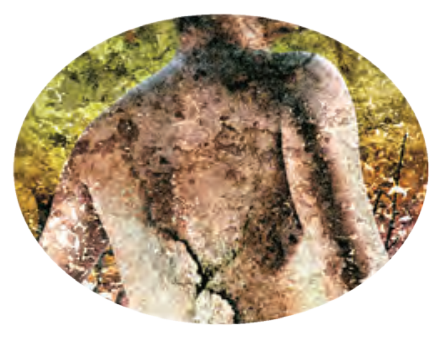

Kércia Priscilla Figueiredo Peixoto* Rodrigo Peixoto

\section{Resumo}

No oeste do Pará, comunidades se autorreconheceram indígenas para conquistar o direito de permanecer no território onde sempre viveram e que determinaram como Terra Indígena Maró. A TI Maró está inserida na última área de floresta contínua do Estado do Pará, sendo disputada por diversos interesses. Com o avanço da fronteira econômica, os indígenas sofrem pressão sobre o território cuja demarcação reivindicam. Ali, o Estado se faz presente favorecendo os interesses do capital. Após intensos conflitos, o Ministério Público Federal determinou a publicação do Relatório de Reconhecimento da TI Maró pela FUNAI. O relatório foi publicado em outubro de 2011. O governo do Estado contestou. Os madeireiros propuseram um acordo: abrem mão do pedaço de terra disputado, contanto que os indígenas afirmem que ali não existe conflito. É a estratégia dos madeireiros para ganharem a certificação que anseiam.

Palavras-chave: Terra Indígena Maró; território; fronteira econômica; madeireiro

\footnotetext{
* Mestre pelo Programa de Pós-Graduação em Serviço Social - PGSS da Universidade Federal do Pará UFPA.

** Doutor no Programa de Pós-Graduação em Ciências Sociais da UFPA e pesquisador no Museu Paraense Emílio Goeldi/MCT.
} 


\section{Abstract}

In western Pará, selfrecognize indigenous communities to earn the right to stay in the territory where they have always lived and determined how Indigenous Maró. IT Maró is inserted into the last area of continuous forest in Pará State, being fought over by various interests. With the advance of economic, indigenous people suffer pressure on whose territory demarcation claim. There, the state is present favoring the interests of capital. After intense fighting, the Federal Public Prosecutor ordered the publication of the Report of the Recognition IT Maró by FUNAI. The report was published in October 2011. The state government challenged. Loggers have proposed a deal: give up the disputed piece of land, as long as the Indians claim that there is no conflict there. It is the strategy of the timber to gain the certification they crave.

Keywords: Indigenous Maró; territory; economic frontier; timber

\section{Introdução}

A Terra Indígena Maró foi formada a partir de um processo de autorreconhecimento indígena levado a efeito por três comunidades na gleba Nova Olinda, oeste do Pará. Tais comunidades estão estabelecidas naquele espaço territorial desde que seus antepassados indígenas, opondo-se à submissão imposta pelos "brancos", refugiaram-se naquela floresta como garantia de sua reprodução social e cultural. Os rituais indígenas passaram a ser praticados veladamente e, com o passar do tempo, muitos deles foram se perdendo. Logo, a população que vivia na floresta foi chamada de cabocla, termo pejorativo que significa "aqueles que são do mato" (ARENZ, 2011). No entanto, o termo "caboclo" foi imposto de fora para dentro e as populações nativas não se denominavam como tais.

As comunidades viviam como seres "invisíveis" na floresta, completamente desamparadas pelo poder público. Ali, produziam sua farinha, caçavam, praticavam festas e rituais e se reproduziam. Quando informados sobre a possibilidade de perder o direito a terra em que viviam, e de que uma das formas de garantir seu território seria a possibilidade de se autorreconhecerem indígenas, três comunidades resolveram aderir ao movimento indígena ${ }^{1}$ que vigorava na região do baixo Tapajós. Não tardou para que os conflitos pelo 
território começassem. As comunidades foram "invadidas" por homens munidos de GPS que marcavam e demarcavam a terra como deles.

Eram os "permutados", fazendeiros do Sul do Brasil, que receberam do Governo do Estado do Pará áreas da gleba Nova Olinda como permuta por terras que haviam perdido no sul do Pará. O documento de permuta estabelecia aos beneficiários o dever de demarcar suas terras e as das comunidades vizinhas. Esse abuso ocasionou um forte sentimento de injustiça e foi o estopim para o conflito.

Diante do desrespeito sofrido, os indígenas resolveram agir. Em ação coletiva com instituições aliadas, tomaram emprestado um GPS e se organizaram para entrar na floresta e demarcar o seu território, que denominaram como Terra Indígena Maró. De acordo com relatos de campo, dias antes dessa ação de autodemarcação da terra, capangas de madeireiros sequestraram o cacique Odair José, liderança indígena conhecida como cacique Dadá, e o torturam como tentativa de intimidação. Isso gerou nova revolta e indignação no grupo, mas o muniu de forças para lutar. Afinal, território é espaço de vida e identidade e no caso dos indígenas da TI Maró, perder o território é desaparecer (BONNEMAISON e CAMBRĖZY, apud HAESBAERT, 2006). Na TI Maró não se trata somente de uma luta pela terra, mas também de uma luta pela vida.

É nesse contexto que se aplica a teoria do reconhecimento de Axel Honneth e sua "gramática moral dos conflitos sociais". A luta na TI Maró se configura como uma luta pela sobrevivência motivada por um ato de desrespeito social, sofrido pela ameaça ao território e por sua vez à identidade coletiva. Portanto, trata-se de "um modelo de conflito que começa pelos sentimentos coletivos de injustiça” (HONNETH, 2009: 261), que parte de uma experiência moral de denegação jurídica e social (Idem). O trabalho elucidará como a partir de uma situação de injustiça, as comunidades se organizaram, fortaleceram-se e lutaram para a conquista e vida na Terra Indígena Maró. As comunidades, que antes viviam em silêncio à margem dos direitos básicos negligenciados pelo Estado, agora lutam pelo reconhecimento e pela demarcação do seu território. 


\section{A TI Maró e o significado da natureza: vida para uns, cobiça para outros}

O oeste do Pará, em termos sociológicos, caracteriza-se como uma região de fronteira de expansão da sociedade nacional e do capital, que lhe dita o ritmo de expansão e avança abrindo e pavimentando estradas, projetando um complexo de hidrelétricas no rio Tapajós, instalando grandes projetos de mineração, assim como o agronegócio, que sobe pela BR-163 desde o Mato Grosso em direção ao Pará, ávido de terras férteis. Para a fronteira vêm migrantes em busca de oportunidades de trabalho e de investimento. Entre esses, pecuaristas e madeireiros, que visualizam negócios lucrativos e nem sempre idôneos nessa espécie de faroeste, onde a lei vige apenas precariamente.

Em nome da ocupação econômica da fronteira se toleram ilegalidades e violências na atmosfera, uma vez assim caracterizada pelo então ministro Delfim Netto com uma pérola do discurso oficial: "Vamos fazer da Amazônia um faroeste, depois chamamos o xerife". Esse laissez-faire é parte de uma espécie de planejamento que permite conformar o espaço segundo a lei do mais forte. O conflito engendrado na TI Maró diz respeito ao significado atribuído à natureza: meio e espaço de vida para os indígenas e objeto de exploração para os que cobiçam aquela área. Esse cenário de injustiça suscitou a luta por reconhecimento.

$\mathrm{Na}$ região, a exploração madeireira avança disputando terras com unidades de conservação, projetos de assentamento e terras indígenas. ${ }^{2}$ A Terra Indígena Maró localiza-se na gleba Nova Olinda, que possui 182 mil hectares e que compõe um conjunto de cinco terras arrecadadas e matriculadas em nome do Estado do Pará, formando as glebas Mamuru Arapiuns. Essas terras perfazem um total de um milhão e 312 mil hectares de mata nativa envolvendo os municípios de Juruti, Santarém e Aveiro, corresponde a última área de floresta contínua do Estado do Pará (Figura 1).

Povoada por dezenas de comunidades, que garantem ali sua reprodução social, as glebas Mamuru Arapiuns passam por lento processo de regularização fundiária. Não obstante a parca fiscalização dos órgãos de proteção existentes, os que cobiçam a floresta para explorá-la a qualquer custo encontram agora uma dificuldade: indígenas plenos de direitos reivindicam território, contestam destinações territoriais feitas pelo governo do Estado, concessões florestais e zoneamentos ecológico-econômicos, e defendem a sua terra. É o movimento 
indígena configurando uma questão política importante e enfrentando a exploração madeireira ilegal.

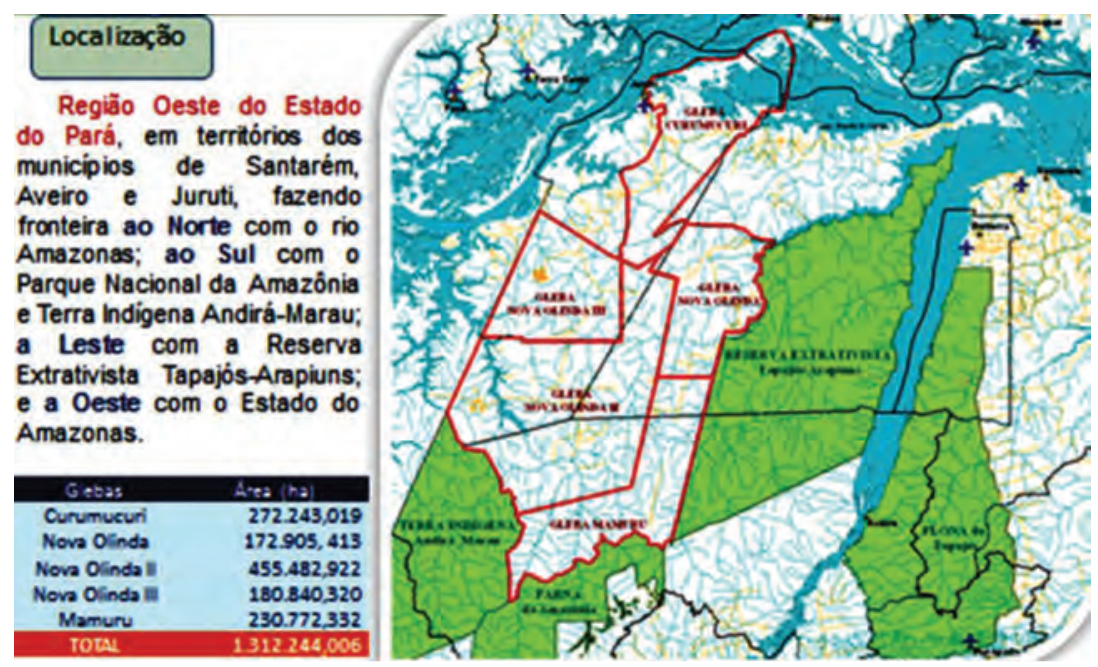

Figura 1 - Localização da Terra Indígena Maró.

Fonte: Ideflor, Sema, Iterpa, Governo do Estado do Pará (2008).

A gleba Nova Olinda está situada na origem do rio Arapiuns, que é formado pela bifurcação de dois rios: o Maró, à esquerda, e o Aruã, à direita. Nas matas do Maró e do Aruã operam empresas madeireiras que empregam mão de obra de comunidades ali situadas. O Aruã é território proibido para os indígenas das aldeias do rio Maró, cujas lideranças são ameaçadas de morte. No rio Maró estão situadas três aldeias: São José III, Cachoeira do Maró e Novo Lugar, que se autodefiniram indígenas e lutam agora pela homologação de seu território. As três aldeias formam a Terra Indígena Maró. Os índios Borari e Arapium, que reivindicam a homologação e a desintrusão da TI Maró, informam que madeireiros ainda mantêm projetos de manejo na terra indígena, marcando e retirando árvores, que seguem em grandes balsas pelos rios Arapiuns e Tapajós.

\section{A etnogênese na TI Maró e o movimento indígena no baixo Tapajós}

A história ${ }^{3}$ de Novo Lugar e de alguns povoados próximos tem cerca de 130 anos. Os índios Borari viviam em Alter do Chão, no Atodi, quando viram 
suas terras tomadas pela "grande migração", durante o ciclo da borracha. Decidiram, então, subir o rio para encontrar um lugar onde pudessem garantir sua sobrevivência e reprodução social. Inicialmente não se instalaram na beira do rio Maró, entraram mais ao interno e se organizaram em Bejuaçu, ${ }^{4}$ em uma das "vidas", como eles denominam as nascentes da terra indígena. Dentro da mata, os indígenas mantiveram vivos os seus rituais, mesmo que os praticando de forma velada, porque sofriam forte discriminação. Garantem que a raiz do índio está na pajelança e que a comunidade sempre praticou os rituais de cura. O grupo, ao longo do tempo, nunca deixou de se organizar sob a liderança de uma sucessão de caciques.

Fato decisivo para a história do grupo ocorreu em janeiro de 2002, quando a comunidade recebeu uma visita inesperada, que viria mudar a sua perspectiva de vida. Uma equipe da Igreja Católica, liderada pela irmã Manoela, do Conselho Indigenista Missionário - Cimi - reuniu-se com a comunidade e informou como a Constituição Brasileira ampara os direitos dos povos indígenas. Explicou sobre a possibilidade do autorreconhecimento étnico, direito que sustentava o movimento indígena, a qual outras comunidades da região estavam aderindo.

A etnogênese no baixo Tapajós faz parte de uma tendência de emergências étnicas que alcança várias experiências no mundo. Embora apresente particularidades, o processo de emergência étnica dessa região está em sintonia com a retomada de tradições por grupos étnicos, então considerados aculturados ou extintos, em todo o Brasil e América Latina. De acordo com Bartolomé, vários casos de etnogêneses latino-americanas se manifestaram nas últimas décadas, afirmando tratar-se "da dinamização e da atualização de antigas filiações étnicas às quais seus portadores tinham sido induzidos ou obrigados a renunciar" (2006: 45).

Os povos indígenas, sendo sujeitos coletivos de direitos, têm direito à autodeterminação conforme a Constituição Federal de 1988 e na Convenção 169, da Organização Internacional do Trabalho, sobre Povos Indígenas e Tribais, adotada em Genebra, em 27/6/1989, reconhecida pelo Estado brasileiro. Na Convenção 169, o art. 1. é fundamental, pois reza que "A consciência de sua identidade indígena ou tribal deverá ser considerada como critério fundamental para determinar os grupos aos que se aplicam as disposições da presente Convenção". Essa prerrogativa, respaldada na "história centenária 
dos primeiros habitantes indígenas que vieram fazer parte da colonização do baixo Tapajós" (FUNAI, 2009), está na base da revitalização da condição étnica no baixo Tapajós e no rio Arapiuns.

Da vergonha de ser ao orgulho ${ }^{5}$ de assumir-se, ocorreu dos anos de 1970 para cá uma drástica guinada, à qual Eduardo Viveiros de Castro dá a sua impressão:

\begin{abstract}
Antigamente, muitos coletivos indígenas sentiam vergonha de sê-lo, e o governo tinha todo interesse em aproveitar essa vergonha inculcada sistemicamente, tirando as consequências jurídico-políticas, digamos assim, do eclipsamento histórico da face indígena de várias comunidades 'camponesas' do país. Agora, ao contrário, 'todo mundo quer ser índio’ - dizemos, entre intrigados e orgulhosos (CASTRO, 2006: 43).
\end{abstract}

Nos grupos indígenas da TI Maró, o orgulho de assumir-se diz respeito ao pertencimento a um grupo no qual a experiência de distinção social está relacionada à própria identidade e resistência coletiva. Honneth (2009) explica que uma experiência de reconhecimento desse tipo corresponde a "um sentimento de orgulho do grupo ou de honra coletiva; o indivíduo se sabe aí como membro de um grupo social que está em condição de realizações comuns, cujo valor para a sociedade é reconhecido por todos os seus demais membros" (HONNETH, 2009: 209).

Segundo Edviges Ioris (2005: 284), o movimento indígena na Flona Tapajós surgiu, entre outras circunstâncias, como reação à identidade genérica de população tradicional imposta pelo governo, cuja definição era fundamentalmente baseada em critérios ecológicos e não socioculturais. De acordo com a autora, não foi apenas para permanecer em suas terras que as comunidades indígenas engajaram-se na luta, mas também para exercer um particular modo de vida que a categoria população tradicional negava. Reclamando antigas referências culturais como um modo de distanciar-se dessa genérica e externamente imposta identidade, os índios Mundurucu, das aldeias Takuara, Marituba e Bragança, redirecionaram suas prévias formas de luta pela terra, voltando-se para a Funai em busca de ter seus territórios oficialmente reconhecidos como Terras Indígenas. Assim, identificando-se como Mundurucus, eles precipitaram uma diferente definição dos espaços 
territoriais na Flona Tapajós e daí em toda a região.

Na TI Maró, relata o cacique Dadá: “o pessoal se reconheceu, mas para nós não existe isso [de se reconhecer]: a gente nascemo e sempre fomos indígena". Com a informação sobre a possibilidade de autorreconhecimento, porém, a comunidade ficou sabendo dos seus direitos. No mês seguinte em que reconheceram indígenas, seis empresas madeireiras entraram com pedido de integração de posse das terras. Foi então que as comunidades se deram conta de que estavam perdendo suas terras e assim se organizou para iniciar a luta.

\section{Identidade e desrespeito: violação, privação de direitos e degradação na TI Maró}

Uma das primeiras iniciativas dos indígenas para garantir a permanência no território foi realizar uma autodemarcação. O cacique Dadá ajudou a organizar os homens das três comunidades da TI Maró para demarcar a área. "Na verdade, o nosso objetivo não era demarcar o mapa, mas abrir os ramais abertos pelos meus bisavôs", afirma o cacique. Mesmo tendo sido desaconselhados pelo Ministério Público, escreveram uma carta aos órgãos competentes informando que começariam a demarcar por conta própria. Uma pequena equipe de comunitários pegou instruções sobre a utilização do GPS na ONG Projeto Saúde e Alegria (PSA) e tomou emprestado um aparelho. Além disso, conseguiu a quantia de dois mil reais com a Comissão Pastoral da Terra (CPT), dinheiro que serviu para comprar alimentos e munição para sustentar os homens que fariam a incursão na mata.

Faltando três dias para começar os trabalhos de demarcação, capangas dos madeireiros prenderam e torturaram o cacique Dadá, das 10 horas da manhã às $5 \mathrm{da}$ tarde, mantendo-o sob a mira de duas armas de fogo. Dadá relembra: "subi pra cá doente, sem andar, provocando sangue. O pessoal aqui com raiva. Mas eu disse não é matar ninguém, é pra retomar a nossa terra”. Esse foi o primeiro de muitos outros ataques sofridos por lideranças das três comunidades. O processo contra os torturadores corre até hoje na Justiça, mas “a Justiça pra nós é lenta, a gente não tem grana pra fazer ela valer. E eu sou proibido de estar na minha própria terra por ordem judicial, de ir pro rio Aruã, de ir pro final da TI, sob ameaça", completa Dadá. 
O desrespeito sofrido pelos indígenas se relaciona às três formas de desrespeito - violação, privação de direitos e degradação - elaboradas por Honneth como resposta à questão de "como a experiência de desrespeito está ancorada nas vivências afetivas dos sujeitos humanos, de modo que possa dar, no plano motivacional, o impulso para a resistência social e para o conflito, mais precisamente, para uma luta por reconhecimento?" (HONNETH, 2009: 214). Foi a denegação dos direitos sobre a terra e o descaso pelas comunidades que ali viviam que deu o impulso inicial à resistência e ao conflito instaurado na região. A violação sofrida, no entanto, sob a forma de tortura pelo cacique Dadá e posteriormente por outras lideranças indígenas, ao mesmo tempo em que criou um profundo sentimento de humilhação, ${ }^{6}$ gerou um sentimento ainda mais forte de lutar pela causa coletiva. Juntamente à privação de direitos e a violação sofrida pelos indígenas, sucedeu a "ofensa" ou "degradação", pois os que cobiçam aquelas terras e os interessados pelo malfadado "progresso" da região se articularam com a imprensa local, ${ }^{7}$ que passou a publicar inúmeras matérias que negavam a identidade indígena daquela população e depreciavam seu modo de vida e sua causa.

Honneth compara os sentimentos de rebaixamento e humilhação social, que ameaçam a identidade do ser humano, com as doenças que ameaçam o seu corpo físico. As reações emocionais negativas se expressam na vergonha social. Na comparação com a saúde física, o autor considera que da mesma forma que agimos a fim de evitar doenças, as relações de reconhecimento seriam capazes de proteger os sujeitos do sofrimento de desrespeito de maneira mais ampla. Desse modo, "as reações negativas que acompanham no plano psíquico a experiência de desrespeito podem representar de maneira exata a base motivacional afetiva na qual está ancorada a luta por reconhecimento" (Ibidem, p. 220). Diante do desrespeito sofrido, os indígenas elaboraram estratégias para lutar e buscaram apoios de aliados para que alcançasse seu objetivo, pois a "tensão afetiva em que o sofrimento de humilhações força o indivíduo a entrar só pode ser dissolvida por ele na medida em que reencontra a possibilidade da ação ativa” (Ibidem, p. 224). O apoio de instituições aliadas foi determinante para que o potencial cognitivo, inerentes aos sentimentos de vergonha social e da vexação, se tornasse convicção política e moral dos indígenas da terra Maró.

Foi com o apoio de um conjunto de organizações - Cimi, Cita, PSA, 
CPT e Grupo de Trabalho Amazônia (GTA) - que as três comunidades demarcaram a TI Maró, elaborando de modo participativo um primeiro mapa. A iniciativa dessa primeira cartografia demonstra a emergência dos indígenas como sujeitos políticos e a importância das alianças políticas. Em cenário de disputas cartográficas, o fato de possuir uma representação cartográfica de si mesmos tem se mostrado fundamental para encaminhar a garantia de direitos territoriais. Diferentemente do conflito nas outras comunidades vizinhas, onde se configura uma luta pela terra, as aldeias de Novo Lugar, São José III e Cachoeira do Maró lutam pela terra, base física, mas também pelo significado existencial do território. Assim, sujeitos políticos, tomando a iniciativa de suas ações, os indígenas da TI Maró se afirmam, étnica e territorialmente, "como forma de neutralizar as pressões sobre seus territórios, ao mesmo tempo em que tentam dar visibilidade aos conflitos que opõem práticas espaciais distintas" (FISHER, 2010: 175).

Nas disputas cartográficas verificadas na gleba Nova Olinda, para os indígenas, tomar a iniciativa de mapear-se, fazendo-se visível, representou uma atitude capaz de impedir que lhes excluíssem do mapa. De forma que também no baixo Tapajós, a exemplo de outras mobilizações na América Latina (ACSELRAD, 2010), a produção de mapas tem instrumentalizado a luta por afirmação territorial (COLI, 2010). Significa dizer que as representações territoriais produzidas por organizações indígenas têm superado o caráter meramente técnico das demarcações, antes executadas somente pelo Estado, para ganhar um sentido político capaz de conferir aos indígenas a condição de sujeitos políticos (PACHECO DE OLIVEIRA, 2006).

\section{O Estado indutor do conflito e do desmatamento}

No ano de 2006, o então governador do Estado do Pará, Simão Jatene, autoriza, pelo Decreto n. ${ }^{\circ}$ 2.472/2006, o assentamento na gleba Nova Olinda. O assentamento é destinado aos "permutados", fazendeiros do Sul do país que adquiriram títulos fundiários do governo do Pará na década de 1980 com o incentivo oferecido pelo Iterpa, no âmbito do projeto Trairão, no município de São Félix do Xingu. No entanto, a Funai determinou em 1990, por meio do Decreto n. ${ }^{\circ}$ 98.865/1990, que essas terras, secularmente ocupadas pelos índios Kayapós, constituíam uma área imemorial indígena, determinando a imediata 
retirada dos ocupantes exógenos. Forçados a sair, os fazendeiros exigiram do governo do Estado a indenização dos valores pagos para a aquisição daquelas terras ou uma área de permuta como compensação. Para eles foi destinada parte da gleba Nova Olinda, ocupada por dezenas de comunidades amazônicas. Esse foi o estopim para a série de conflitos que se instalou na região:

\footnotetext{
As permutas trouxeram em seu bojo a ocorrência de crime de pistolagem, ameaças às lideranças locais, retirada ilegal de madeira, alteração nos costumes locais, caça altamente predatória, que está sendo exercida pelos funcionários dos "permuteiros" que trabalham na extração de madeira, e uma certeza de que ocorrerá o desmatamento futuro destas áreas (STTR \& CPT, 2008: 26).
}

Entre os anos de 2002 e 2006, deu-se início a uma desenfreada ocupação no conjunto de glebas Mamuru Arapiuns, visando à exploração madeireira, processo esse comandado pelo governo, que se apoiava em dois instrumentos jurídicos: as Adips (Autorizações para Detenção de Imóveis Públicos) e a celebração de escrituras públicas de permuta. As Adips foram concessões estaduais de uso da terra que formalizavam o direito à exploração dos recursos naturais, impedindo que a situação fundiária fosse um empecilho para a atividade madeireira, desconsiderando deliberadamente a ocupação tradicional da área e a fragilidade ambiental. As escrituras de permuta garantem juridicamente o assentamento dos permutados em terras de usos de populações tradicionais. O documento de escritura de permuta concedido pelo governo atribui aos permutados a tarefa e realizar a autodemarcação e o georreferenciamento de suas terras e das terras vizinhas das populações tradicionais.

Dessa forma, o governo se livra da sua obrigação de mapear e delimitar, concedendo aos principais interessados uma função que deveria ser sua. Esse fato fez com que as comunidades se sentissem indignadas, aguçando ainda mais o conflito na região. $\mathrm{Na}$ aldeia de Novo Lugar, os comunitários relatam que os madeireiros chegaram dotados de GPS e foram invadindo o território sem pedir autorização. Foram marcando e demarcando, sem dar explicações, como se a terra fosse deles. E assim se apropriaram de área do final da TI Maró, onde é grande a incidência da árvore mururé, da qual os indígenas extraem uma seiva medicinal. Os indígenas, por sua vez, como já relatado 
acima, autodemarcaram a sua terra, colocando-a no mapa, com essa fração de terra incluída. Reivindicam uma área de 42 mil hectares. No limite dela estão os permutados, que demandam 15 mil hectares dentro da TI Maró. Essa é a disputa que instiga o principal conflito territorial da região.

A fim de amenizar a situação, o governo seguinte, do Partido dos Trabalhadores, consolida, no conjunto de glebas Mamuru Arapiuns, pelo Decreto n. ${ }^{\circ}$ 1.149/2008, a Alap - Área de Limitação Administrativa Provisória. O documento impedia, no seu art. $2 .^{\circ}$, as atividades e empreendimentos efetiva ou potencialmente causadores de degradação ambiental, assim como vetava atividades relacionadas ao corte raso da floresta e da vegetação nativa. O documento que instituía a Alap, proibia também atividades relacionadas ao uso direto dos recursos naturais, exceto aquelas ligadas a atividades sustentáveis, historicamente realizadas por comunidades tradicionais.

Por outro lado, a promulgação da lei federal de gestão de florestas públicas permitia ao governo, a regularização da exploração madeireira por procedimentos de concessão florestal. Antes da formalização das concessões, porém, a lei obrigava que as florestas públicas ocupadas ou utilizadas por comunidades locais fossem identificadas para a destinação, seja pela criação de reservas extrativistas e/ou de desenvolvimento sustentável, bem como por transferência de uso, seja por meio de assentamento florestal, assentamento de desenvolvimento sustentável, agroextrativistas ou similares. A promulgação dessa lei significou a viabilização do processo de ordenamento fundiário no conjunto de glebas Mamuru Arapiuns. No entanto, Fisher (2010) faz uma importante avaliação:

\footnotetext{
"A regularização fundiária dos territórios tradicionalmente ocupados pode ser vista como um mecanismo de dupla eficácia, uma vez que garante os direitos territoriais pleiteados por comunidades tradicionais, ao mesmo tempo em que, paralelamente, titula, estabiliza e insere no mercado novas terras, que são passíveis de serem incorporadas às frentes de acumulação do capital" (FISHER, 2010: 173).
}

\section{Ação coletiva para a conquista do território}

Quando o governo instituiu a Alap, por meio de comissão formada por três órgãos estaduais (Ideflor, Sema e Iterpa), pretendia um processo 
participativo, de forma que as comunidades indicassem as modalidades de destinação pleiteadas. Antecipando-se ao governo, as comunidades, apoiadas pelo STTR/Santarém e pela CPT, e com a colaboração do Ibama e do projeto Saúde e Alegria, organizaram um seminário (13 e 14/11/2008) para discutir a Alap. No "Seminário de Elaboração Participativa de Mosaico de Uso da Terra na Alap Nova Olinda/Mamuru no Oeste do Pará", 51 comunidades elaboraram um mapa participativo, fazendo valer seus conhecimentos para o diagnóstico e planejamento daquele espaço. Os comunitários apontaram suas áreas de uso e os limites de suas comunidades, baseados na localização de rios e igarapés. No mapa indicaram as modalidades de titulação mais convenientes a cada comunidade. Com essa iniciativa, as comunidades se respaldaram diante do governo para o processo de destinação territorial nas glebas Mamuru Arapiuns:

Os mapas participativos permitem a documentação da realidade pelos grupos sociais que sempre passaram despercebidos pelos mapas e documentos oficiais, tornando visíveis os conflitos e reivindicações. Configuram-se como uma estratégia de ação coletiva garantindo o direito a terra e a conservação dos recursos naturais utilizados direta ou indiretamente (STTR/Santarém \& CPT, 2008: 9).

O mapa alicerçou o "Plano Participativo de Mosaico de Uso da Terra nas Glebas Nova Olinda, Nova Olinda II e III, Cumurucuri e Mamuru no Oeste do Pará" (STTR/Santarém \& CPT, 2008) e indicou cinco Projetos Estaduais de Assentamento Extrativistas $(\text { Peax })^{8}$ - Curumucuri, Mamuru, Aruã, Vista Alegre e Mariazinha; três Projetos Estaduais de Assentamento Sustentável (Peas) ${ }^{9}$ - Aruã-Maró, Fé em Deus e Repartimento; o Parque Estadual do Mamuru; a Floresta Estadual do Alto Aruã (Unidade de Conservação de Uso Sustentável); e a Terra Indígena Maró. No caso da TI Maró, as três comunidades indígenas (Cachoeira do Maró, Novo Lugar e São José III) decidiram, após debates e reflexões, que as categorias "Projetos de Assentamento" e "Unidades de Conservação" não condiziam aos seus objetivos de garantia do território. 

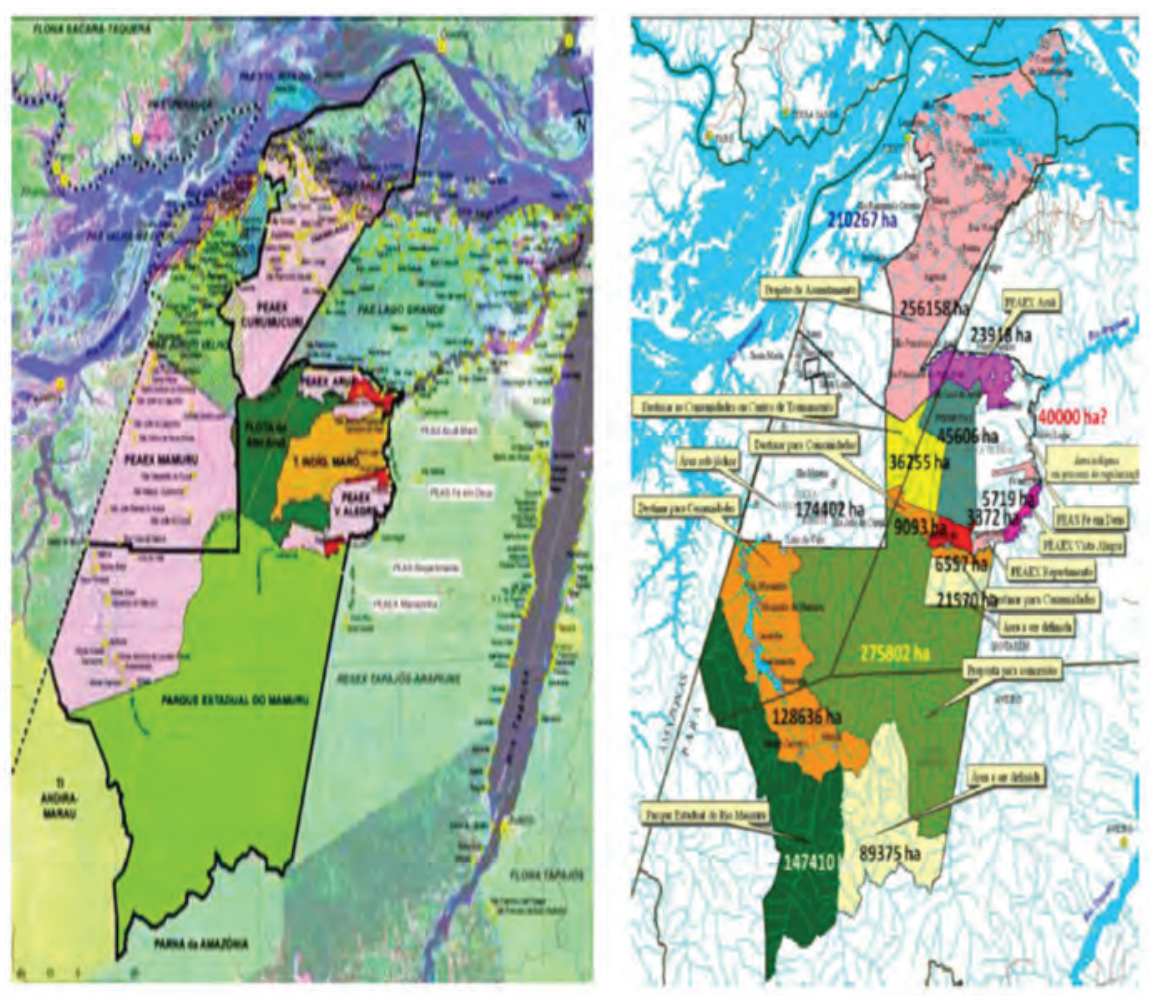

Figura 2 - Plano Participativo de Mosaico de Uso da Terra nas Glebas Nova Olinda, Nova Olinda II e III, Cumurucuri e Mamuru no Oeste do Pará

Fonte: STTR \& CPT, 2008; Sema, Iterpa, Ideflor, 2009.

As representações cartográficas acima, a primeira produzida pelas comunidades e seus aliados, e a segunda pelo governo, mostram que o esforço não foi em vão. As demandas comunitárias relativas aos assentamentos e uma reserva de área à TI Maró foram acatadas. O governo destinou áreas ambientais para exploração madeireira, porém.

$\mathrm{Na}$ gleba Nova Olinda estão 15 comunidades, entre elas algumas cooptadas pelos madeireiros. De um lado, as que buscam a afirmação de sua identidade e de seu território, de outro as seduzidas pelos benefícios oferecidos pelos madeireiros, como empregos na extração da madeira, salários e geradores de energia. Em contrapartida, essas comunidades demandam terras menores e titulações individuais no processo fundiário em curso. As comunidades resistentes expressam indignação contra quem, segundo elas, "se vende" para 
os madeireiros. Enormes balsas carregadas de toras de madeira continuam descendo o rio Arapiuns. E a madeira agora escoa também por rotas terrestres. O conflito se acirra.

\section{Atribuindo significados ao território Maró}

Em um primeiro momento de observações foi constatado o emprego pelos indígenas da palavra território. Em uma reunião, em Cachoeira do Maró, com lideranças das três comunidades e alguns membros do Conselho Indígena Intercomunitário Arapium e Borari (Coiiab), ouvimos as afirmações: "O território acabou há muito tempo", "Queremos resgatar o nosso território", "O território foi dividido", "É um espaço indígena que estamos tentando recuperar". Perguntamos o que significa território para eles. Um deles se antecipou e respondeu: "O território inclui tudo: a vida, o espaço, a terra do ser humano, dos animais, da floresta”. É notável a coincidência com a ideia de território utilizada por Haesbaert (2006), que inventaria várias linhas de interpretação. Território é lugar de hibridação entre sociedade e natureza, entre elementos materiais e imateriais, o saber fazer, o modo de vida, o simbólico, a existência de mecanismos de solidariedade.

Considerando a luta pela TI Maró, o pensamento de Milton Santos (2006) sobre território usado relaciona chão com identidade e condiz com aquele lugar:

O território não é apenas o conjunto dos sistemas naturais e de sistemas de coisas superpostas; o território tem que ser entendido como território usado, não o território em si. O território usado é o chão mais a identidade. A identidade é o sentimento de pertencer àquilo que nos pertence. $\mathrm{O}$ território é o fundamento do trabalho; o lugar da residência, das trocas materiais e espirituais e do exercício da vida (SANTOS, 2006: 14).

A conquista da TI Maró se relaciona diretamente à sobrevivência do grupo. A ligação dos povos tradicionais com o território significa a própria existência: 
Pertencemos a um território, não o possuímos, guardamolo, habitamo-lo, impregnamo-nos dele. Além disso, os viventes não são os únicos a ocupar o território, a presença dos mortos marca-o mais do que nunca com o signo sagrado. Enfim, o território não diz respeito apenas à função ou ao ter, mas ao ser. Esquecer este princípio espiritual e não material é se sujeitar a não compreender a violência trágica de muitas lutas e conflitos que afetam o mundo de hoje: perder seu território é desaparecer (BONNEMAISON e CAMBRĖZY, apud HAESBAERT, 2006: 51).

Os Borari e os Arapium não querem desaparecer. Perder a terra é enterrar a história, os lugares sagrados, a vida como povo. Cansados de ver subir pelos rios balsas carregadas de madeira, e de denunciar o fato às autoridades, sem nenhum resultado, indígenas e comunitários resolveram agir por conta própria. No dia 10 de novembro de 2009 , em ação coletiva, queimaram duas balsas carregadas de madeira supostamente ilegal. A carga foi avaliada em 5 milhões de reais e queimou por três noites. O fato foi um divisor de águas e marcou a história daquele lugar. As comunidades perceberam que podiam se insurgir. Isso fortaleceu o movimento. Por outro lado, a tensão aumentou após o incêndio. Madeireiros contrariados passaram a incentivar o ódio étnicoracial na população local. Alguns jornalistas da imprensa santarena veiculam matérias alegando que os indígenas não são verdadeiros, pois, segundo eles, a etnia Borari já está extinta há duzentos anos. Essas matérias apontam os indígenas como responsáveis pelo atraso econômico da região, acusando-os de inviabilizar o uso produtivo das terras regionais. Desde então, a reação ao movimento indígena se fez mais forte, inclusive com contestações ${ }^{10}$ a processos demarcatórios de terras por parte de órgãos governamentais, como Ibama e ICMBio. A reação contra o movimento indígena se institucionalizou.

Com a manifestação da queima das balsas, o Ministério Público Federal em Santarém iniciou uma Ação Civil Pública para acompanhar o processo de demarcação. O processo administrativo de demarcação da TI Maró foi iniciado em 2004 pela Funai. A Funai, porém, tardou em publicar o Relatório de Identificação e Delimitação. Os indígenas ansiavam por essa publicação, pois é esse o documento que definiu o reconhecimento formal e o tamanho da área da TI. Depois de uma longa espera, em 8 de junho de 2011, a Justiça 
Federal em Santarém determinou à Funai que publicasse em trinta dias o relatório de identificação e delimitação da TI Maró, sob pena de multa diária no caso de descumprimento. Finalmente, em outubro de 2011, o Relatório foi publicado e em seguida contestado pelo Governo do Estado do Pará, por meio do Iterpa.

\section{Considerações finais}

No movimento indígena do baixo Tapajós, a conquista da Terra Indígena Maró é fato relevante. A TI Maró sofre pressões da indústria madeireira, que tem dezenas de projetos de manejo florestal na gleba Nova Olinda, alguns dentro mesmo do território indígena, recentemente reconhecido pela Funai, que em outubro de 2011 publicou seu relatório circunstanciado de identificação e delimitação. Contudo, quem assumiu a contestação, manifestando impugnação ao despacho que abrigou o relatório, foi o Instituto de Terras do Pará (Iterpa), que reivindica a área para madeireiros, a fim de efetivar-se um arranjo de permuta e compensação, promovido pelo governo do Estado.

No Pará, o interesse dos empresários originários do Sul do país é a apropriação de ricas áreas florestais para a realização de extraordinários lucros, já que a fiscalização é notoriamente escassa e permite a retirada de grandes volumes de madeira ilegal. O movimento indígena no baixo Tapajós denuncia a pilhagem, tolerada pelo Estado, que ademais fomentou conflitos ao pôr madeireiros em territórios reivindicados pelos indígenas. Esse é o contexto onde, a despeito das desvantagens de meios, o movimento indígena conseguiu uma conquista relevante, com o reconhecimento pela Funai da Terra Indígena Maró.

Recentemente, em 6/1/2012, o Instituto de Terras do Pará (Iterpa), em referência ao Despacho n. ${ }^{\circ} 107$, da presidência da Funai, publicado no DOU em 10/10/2011, manifestou "impugnação àquele ato", que contraria a iniciativa do governo estadual de situar na TI Maró madeireiros oriundos do projeto Trairão, no município de São Félix do Xingu. O ofício do Iterpa se faz acompanhar de texto intitulado "Flechas Enganosas", em que o autor critica o movimento indígena evocando o fantasma de agentes externos interessados no subdesenvolvimento da Amazônia: "Tais ações indigenistas obedecem a uma agenda geopolítica externa, visando o engessamento de enormes áreas de 
produção e servirem de óbices à realização de obras estruturantes na região, a fim de mantê-la subpovoada e subdesenvolvida”.

Por outro lado, a intrusão de atividades madeireiras na TI Maró e o prejuízo que ela causa aos indígenas e à natureza estão reportados no Relatório Circunstanciado de Identificação e Delimitação da Terra Indígena Maró/PA:

\begin{abstract}
A atuação da indústria madeireira já tem causado assoreamento de cabeceiras de igarapés como o Tirirical, Tobias e Raposa. O comprometimento destas cabeceiras tem consequências negativas relevantes, especialmente para a aldeia de Novo Lugar, local onde todas estas desembocam. No entanto, por ser esta a comunidade localizada a montante, certamente as demais também sofrerão com a diminuição do fluxo do rio Maró e destruição de locais importantes para a reprodução de peixes (FUNAI, 2011).
\end{abstract}

O conflito, ao passo que se dá diretamente com agentes econômicos locais, tem como agente principal o Estado brasileiro, que em lógica desenvolvimentista almeja a integração dos territórios indígenas e seus respectivos recursos naturais aos processos econômicos, apesar da retórica de defesa da pluralidade sociocultural (VERDUM, 2008). Apesar dos avanços conceituais e legais, vigora ainda a prática do velho SPI de 'abertura dos sertões à iniciativa dos particulares' (FREIRE, 2009: 31). Por outro lado, indígenas recentemente assumidos retomam "suas tradições a partir de uma identidade genérica de caboclos já assimilados” (ARRUTI, 1997: 11), fazendose assim sujeitos políticos, subvertendo a indistinção (Ibidem, p. 19) e o projeto geopolítico regional.

Um trecho do relatório de identificação e delimitação da TI Maró se refere a essa situação de conflito, com as cabeceiras dos igarapés, lugares sagrados para os indígenas, com o acesso impedido por cercas e porteiras:

\footnotetext{
"É importante destacar que cientes do processo de usurpação de sua área de ocupação permanente, os Borari e Arapium em 2005 realizaram a primeira autodemarcação de seus limites territoriais em projeto conjunto entre o Conselho Indígena TapajósArapiuns e programa Saúde Alegria. Em 2007 foi realizado o georreferenciamento dos pontos identificados. Os limites
} 
apresentados no mapa de autodemarcação, em alguns momentos, contrastam com as narrativas proferidas pelos indígenas quando da entrada na mata e da utilização dos recursos naturais lá existentes. Alguns igarapés (especialmente suas cabeceiras), como o do Cachimbo e do Arraia, são tidos pelos indígenas como importantes, mas não aparecem nos limites geográficos. Lendo o mapa de autodemarcação, é possível perceber que todos os pontos de conflito e no qual os indígenas se sentem pressionados em seu território não são contemplados, numa nítida reação de medo às ameaças sofridas. (...) Locais sempre utilizados para a caça e pesca hoje têm cercas e portões, coibindo a entrada de estranhos e atividades produtivas. A cabeceira do igarapé do Cachimbinho está fechada com uma porteira" (FUNAI, 2011).

A história dos Borari e Arapium ganhou uma inflexão com o reconhecimento oficial da Terra Indígena Maró. Fato novo é que após o reconhecimento os madeireiros propuseram um acordo: abrem mão do pedaço de terra disputado, contanto que os indígenas afirmem que ali não existe conflito. É a estratégia dos madeireiros para ganharem a certificação que anseiam. Até aqui resistência tem sido uma palavra definidora dessa história, construída com o desejo de pertencer a um povo, a um lugar e a uma luta. A conquista da terra fortaleceu a identidade, que tem a ver com continuidades históricas, inclusive territoriais. Agora eles almejam uma vida melhor sobre o território conquistado. Eles almejam educação e saúde indígenas em padrão superior aos tacanhos serviços atuais, assim como a utilização autônoma dos recursos naturais na terra indígena demarcada, e são movidos por esses direitos. Os indígenas têm consciência de que território é construção.

A vida no território é ainda dependente de auxílios governamentais. "Os principais benefícios recebidos são as aposentadorias como trabalhadores e trabalhadoras rurais e o programa Bolsa Família” (FUNAI, 2011). Dois professores, um agente comunitário de saúde e um auxiliar de serviços gerais recebem como funcionários públicos (Idem). Em um momento da reunião em Cachoeira do Maró, um indígena de Novo Lugar disse: "a gente fez uma conta maluca e constatou que por mês entra na nossa comunidade cerca de $\mathrm{R} \$$ 8.600,00 de aposentadorias e pensões, e esse dinheiro vai parar na mão dos donos dos barcos de linha". Outras despesas importantes são as taxas do dízimo, devidos à Igreja Católica, as taxas do sindicato. A tudo isso se soma as 
coletas do clube de futebol e do clube de mães. Por isso, sentem a necessidade de organizarem-se para, pelo menos, fretarem um barco em conjunto para levar seus produtos à cidade. Sonham que um dia poderão comprar um barco para facilitar a vida nas comunidades.

\section{Notas}

1 Na Floresta Nacional Tapajós (Flona), em 1998, uma comunidade se autodeclarou Munduruku. Esse foi o início do movimento indígena que reivindica direitos indígenas, especialmente a garantia de seu território e o reconhecimento da sua identidade. Atualmente, 48 comunidades se declaram indígenas no baixo Tapajós.

${ }^{2}$ Naquele espaço geográfico estão a Floresta Nacional do Tapajós, a Reserva Extrativista Tapajós-Arapiuns e o Projeto de Assentamento Extrativista Lago Grande, unidades de alçada federal onde o movimento indígena se manifesta.

${ }^{3}$ A história foi relatada por moradores na pesquisa de campo.

${ }^{4}$ Vivendo em Bejuaçu, no interior da mata, longe da beira do Maró, abriram diversas trilhas, fizeram seus roçados, garantiram a extração de resinas medicinais, tinham suas áreas de caça e coleta e mantinham seus lugares sagrados destinados aos seus rituais. No ano de 1990, as mães da comunidade exigiram que os filhos frequentassem uma escola. Para viabilizar a educação das crianças, o grupo concordou em descer para se instalar na margem do rio Maró.

${ }^{5} \mathrm{O}$ movimento cresce não apenas em virtude dos direitos dos povos indígenas, respaldados por legislações internacionais e pela Constituição de 1988, em um quadro de insuficiência de serviços públicos para as comunidades caboclas, desde sempre desprezadas. O indígena, antes envergonhado, se sente orgulhoso de pertencer a um povo e a um movimento que busca afirmar identidades, direitos e territórios. E isso é contagiante (PEIXOTO, 2011).

${ }^{6}$ Considera Honneth que a tentativa de se apoderar de corpo alheio, contra sua vontade, provoca um grau de humilhação que interfere "destrutivamente na autorrelação prática de um ser humano, com mais profundidade do que outras formas de desrespeito", pois o que ocorre na tortura ou violação não é apenas a dor física, mas a sujeição ao outro sem proteção, perdendo até o senso de realidade (Idem, p. 215).

7 Alguns jornalistas da imprensa santarena veiculam matérias alegando que os indígenas não são verdadeiros, pois, segundo eles, a etnia Borari já está extinta há duzentos anos. Essas matérias apontam os indígenas como responsáveis pelo atraso econômico da região, acusando-os de inviabilizar o uso produtivo das terras regionais.

8 “O Projeto Estadual de Assentamento Agroextrativista - Peaex - destina-se a populações que praticam a exploração sustentável dos recursos naturais voltadas para a subsistência. A área é de domínio público com uso concedido às populações extrativistas. A destinação das áreas dá-se por meio de uma concessão de direito real de uso, em regime de uso comum, associativo ou cooperativista por prazo indeterminado" (STTR \& CPT, 2008, p. 13).

9 “Os Projetos Estaduais de Assentamento Sustentável - Peas - abrangem as áreas trabalhadas em regime de economia familiar que utilizam racionalmente os recursos naturais existentes. A destinação das áreas dá-se mediante um contrato de concessão de uso em regime individual, 
em nome da unidade familiar. O contrato de concessão é intransferível e inegociável pelo prazo de dez anos, ao término do qual poderá ser expedido Título Definitivo de Propriedade” (STTR \& CPT, 2008, p. 14).

${ }^{10}$ A Constituição de 1988, art. 67, ordenou a demarcação de todos os territórios indígenas no Brasil, dentro do período de cinco anos após sua promulgação. No entanto, mais da metade dos territórios ainda espera por uma demarcação. Fato decisivo a entravar as demarcações é o Decreto n. ${ }^{\circ} 1.775$, de janeiro de 1996, proposto pelo então ministro da Justiça Nelson Jobim e assinado pelo presidente Fernando Henrique Cardoso. O decreto impôs o chamado princípio do contraditório dentro do processo administrativo. "It provides a legal mechanism for those who also claimed access to indigenous lands to appeal against their demarcation, giving a chance for commercial interests, such as ranchers, miners, and loggers, to present their case" (BORGES \& COMBRISSON, 2011).

\section{Referências}

ACSELRAD, Henri. Mapeamentos, identidades e territórios. In:

(Org.). Cartografia social e dinâmicas territoriais: marcos para o debate. Rio de Janeiro: Universidade Federal do Rio de Janeiro / Instituto de Pesquisa e Planejamento Urbano e Regional, 2010.

ARENZ, Karl. Cartilha da Terra Indígena Maró. Belém: MCT / MPEG / PSA, 2011.

ARRUTI, José Maurício Andion. A Emergência dos “Remanescentes”: Notas para o Diálogo entre Indígenas e Quilombolas. Mana, 3(2):7-38, 1997.

BARTOLOMÉ, Miguel Alberto. As etnogêneses: velhos atores e novos papéis no cenário cultural e político. Mana, 12(1):39-68, 2006.

BORGES, Beto \& COMBRISSON, Gilles. Indigenous Rights in Brazil: Stagnation to Political Impasse. Disponível em: http://saiic.nativeweb.org. Acesso em 20/9/2011.

CASTRO, Eduardo Viveiro de. "No Brasil, todo mundo é índio, exceto quem não é". Povos Indígenas no Brasil 2001/2005. Instituto Socioambiental, agosto de 2006.

FISHER, Wendel. "Conflitos territoriais e disputas cartográficas: tramas sociopolíticas no ordenamento territorial do oeste do Pará". In: Cartografia social e dinâmicas territoriais: marcos para o debate. ACSER ALD, Henri (Org.). 
Rio de Janeiro: IPPUR-UFRJ, 2010.

FREIRE, Carlos Augusto da Rocha. O SPI na Amazônia. Política indigenista e conflitos regionais (1910-1932). Rio de Janeiro: Museu do Índio, 2009.

FUNAI - Fundação Nacional do Índio. Ministério da Justiça. Relatório Circunstanciado de Identificaşão e Delimitação da Terra Indígena Cobra-Grande (Santarém) PA). Janeiro de 2009.

- Relatório Circunstanciado de Identificação e Delimitação da Terra Indígena Maró/PA. Despacho n. ${ }^{\circ}$ 107, outubro de 2011.

HAESBAERT, Rogério. O mito da desterritorialização. Rio de Janeiro: Bertrand Brasil, 2007.

HONNETH, Axel. Luta por reconbecimento: a gramática moral dos conflitos sociais. São Paulo: Editora 34, 2009.

IORIS, Edviges Marta. A Forest of disputes: struggles over spaces, resources, and social identities in Amazonia. A dissertation presented to the Graduate Scholl of the University of Florida in partial fulfillment of the requirements for the degree of Doctor of Philosophy. Universityof Florida, 2005.

OLIVEIRA, João Pacheco de (Org.). Hacia una Antropologia del Indigenismo. Rio de Janeiro: Contracapa, 2006.

OLIVEIRA, João Pacheco de. Uma etnologia dos "índios misturados": situação colonial, territorialização e fluxos culturais. In: OLIVEIRA, João Pacheco de (Org.). A viagem de volta: etnicidade, política e reelaboração cultural no Nordeste indígena. Rio de Janeiro: Contra Capa Livraria Ltda., 1999.

PEIXOTO, Rodrigo. "Indígenas resistentes se movimentam por identidade e território no baixo Tapajós". VII Conferência da Salsa, Belém, 22 a 26 de junho de 2011. No prelo 2011.

SANTOS, Milton. O Dinheiro e o Território. In: Território, territórios - ensaios sobre o ordenamento territorial. Niterói: PPGEO-UFF, DP\&A, 2002, 19.

STTR - Sindicato dos Trabalhadores Rurais de Santarém \& CPT - Comissão Pastoral da Terra. Plano Participativo de Mosaico de Uso da Terra nas Glebas: Nova Olinda, Nova Olinda II, III, Cumurucuri e Mamuru no Oeste do Pará. Santarém, 2008. 
VERDUM, Ricardo. Elindigenismo brasileño en tiempos de multiculturalismo. Alteridades, 2008, 18 (35):33-46. 